\title{
LAYANAN CLOUD COMPUTING BERBASIS INFRASTRUCTURE AS A SERVICE MENGGUNAKAN ANDROID
}

\author{
Hero Wintolo, Lalu Septian Dwi Paradita \\ Program Studi Teknik Informatika \\ Sekolah Tinggi Teknologi Adisutjipto Yogyakarta \\ informatika@stta.ac.id
}

\begin{abstract}
Cloud computing, one form of information technologies are widely used in the field of computer networks or the Internet. Cloud computing consists of computer hardware, computer networking devices, and computer software, the cloud computing there are three services provided include (SaaS) Software as a Service (PaaS) Platform as a Service, and (IaaS) Infrastructure as a Service. Application cloud computing services in the wake of this system is a service-based data storage infrastructure as a service by using android smartphone as a storage medium, which utilizes FTP Server which is already available on the smartphone. This certainly supports the easy storage of data that utilize various types of internal and external storage on smartphones that serves as a storage server. In addition to the functions of storage available, this service can accommodate streaming function .mp3 file type. Implementation result of the system can be implemented on a local network using a wireless LAN. In addition, the results of user testing using Likert method shows the application can run and function properly
\end{abstract}

Keywords: Cloud computing, smartphones, infrastructure as a service, FTP Server.

\section{Pendahuluan}

Cloud computing atau atau "komputasi awan" salah satu bentuk teknologi informasi yang banyak digunakan pada bidang jaringan komputer atau internet. Cloud computing terdiri dari perangkat keras komputer, perangkat jaringan komputer, dan perangkat lunak komputer, dalam cloudcomputing ada tiga layanan yang disediakan antara lain (SaaS) Software as a Service, (PaaS) Platform as a Service, dan (IaaS) Infrastructure as a Service. Layanan - layanan tersebut sudah banyak digunakan oleh orang-orang yang membutuhkan teknologi ini, salah satu contoh layanan cloud computing adalah google drive, yang dapat dimanfaatkan untuk menyimpan data di server google. Pada penelitian ini, layanan - layanan yang biasa digunakan pada personalcomputer (PC) akan diterapkan pada SmartPhone yang berbasis android.

Smart Phone android memiliki fasilitas wireless LAN adapter yang dapat digunakan untuk berkomunikasi dengan perangkat wireless lainnya yang terhubung pada wireless access point (WAP). Dengan wireless access point, beberapa smartphone dirancang membentuk jaringan komputer wireless local area network (WLAN). WLAN berfungsi sebagai media transmisi untuk proses penyimpanan data pada smartphone yang memiliki memori bebas untuk menyimpan data, hal ini membutuhkan kajian yang akan dibahas pada penelitian ini. Data akan disimpan ke beberapa smartphone yang akan digunakan sebagai server dalam sistem, dengan memanfaatkan FTP Server yang sudah tersedia pada smartphone android, user dapat menyimpan, dan mengakses data yang terdapat pada server atau smartphone. Proses streaming juga dapat berjalan pada sistem ini, dengan upload data terlebih dahulu, tetapi hanya dapat melakukan streaming dalam format .MP3, kerja dari sistem ketika melakukan streaming, hampir sama dengan sistem kerja dari youtube, dimana data akan di download terlebih dahulu dibelakang layar lalu di play. 


\section{Metodologi Penelitian}

\subsection{Teknologi Cloud Computing}

Cloud Computing (komputasi awan) merupakan gabungan pemanfaatan teknologi komputer (komputasi) dalam suatu jaringan dengan pengembangan berbasis internet (awan) yang mempunyai fungsi untuk menjalankan program atau aplikasi melalui komputer - komputer yang terkoneksi pada waktu yang sama, tetapi tak semua yang terkonekasi melalui internet menggunakan cloud computing (Alex, 2012).

\subsection{File Transfer Protocol (FTP)}

File Transfer Protocol (FTP) sampai saat ini masih menjadi media favorit yang digunakan untuk melakukan transfer file melalui jaringan internet terutama file-file yang berukuran besar. Hal ini disebabkan media komunikasi seperti email memiliki keterbatasan untuk melewatkan ukuran file yang besar. FTP hanya menggunakan metode autentikasi standar, yakni menggunakan username dan password yang dikirim dalam bentuk tidak terenkripsi. Pengguna terdaftar dapat menggunakan username dan password-nya untuk mengakses, men-download, dan meng-upload berkas-berkas yang ia kehendaki. Umumnya, para pengguna terdaftar memiliki akses penuh terhadap beberapa direktori, sehingga mereka dapat membuat berkas, membuat direktori, dan bahkan menghapus berkas. Pengguna yang belum terdaftar dapat juga menggunakan metode anonymous login, yakni menggunakan nama pengguna anonymous dan password yang diisi dengan alamat e-mail.

\subsection{Android}

Android adalah Platform/aplikasi yang bebas untuk develop. Tidak ada lisensi atau biayaroyalti untuk dikembangkan pada platform Android. Android merupakan generasi baru platform mobile, platform yang memberikan pengembang untuk melakukan sesuai yang diharapkannya.Sistem operasi yang mendasari Android dilisensikan dibawah GNU, General Public Lisensi Versi 2 (GPLv2), yang sering dikenal dengan istilah "copyleft" lisensi dimana setiap perbaikan pihak ketiga harus terus jatuh dibawah term.Android juga didistribusikan di bawah lisensi Apache Software (ASL/Apache2), yang memungkinkan untuk distribusi kedua dan seterusnya.

\subsection{Perancangan Perangkat Lunak}

Penelitian ini dilakukan dalam lima langkah. Langkah pertama adalah kepustakaan yang mempelajari teori-teori dengan membaca beberapa buku yang berhubungan dengan permasalahan yang diambil.Yang kedua adalah mengumpulkan data online yang berupa jurnal dan penelitian yang memiliki korelasi dengan penelitian yang dilakukan.Kemudian langkah ketiga adalah analisa perangkat dan kebutuhan perangkat lunak, perangkat keras, kebutuhan sistem dan kebutuhan pengujian. Langkah ketiga adalah perancangan sistem yang menggambarkan hubungan sistem dengan pengguna, baik dalam bentuk flowchart, dfd, serta interface. Langkah keempat adalah implementasi sistem yang merupakan penerapan rancangan sistem yang akan dibuat sesuai dengan perancangan sebelumnya. Terakhir, langkah kelima adalah pengujian dimana sistem secara keseluruhan yang dibuat telah dapat berjalan dengan benar sesuai dengan tujuan yang ingin dicapai. Adapun rancangan atau arsitektur sistem yang akan dibuat. 


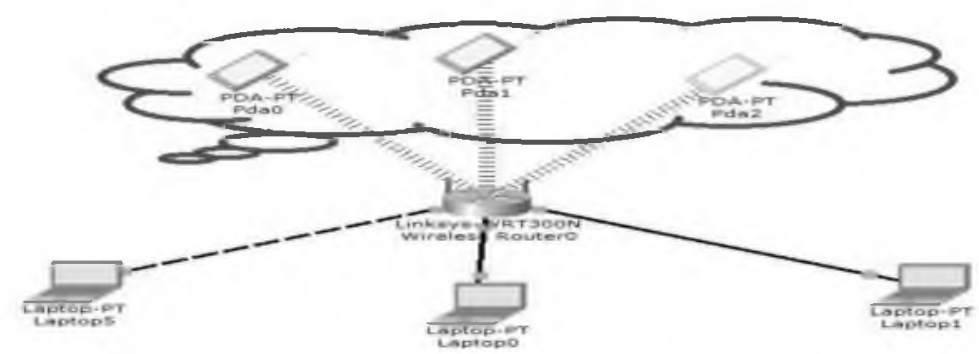

Gambar 1. Rancangan Arsitektur Sistem

\subsubsection{Diagram Konteks}

Diagram ini merupakan diagram yang terdiri dari suatu gambar proses dan menggambarkan ruang lingkup suatu sistem. Diagram ini adalah diagram dengan level tertinggi dari Data Flow Diagram(DFD) yang menjelaskan seluruh input ke sistem atau output sistem sehingga dapat memberikan gambaran tentang keseluruhan sistem. Untuk diagram konteks dari sistem yang dibangun dapat dilihat pada Gambar 1.

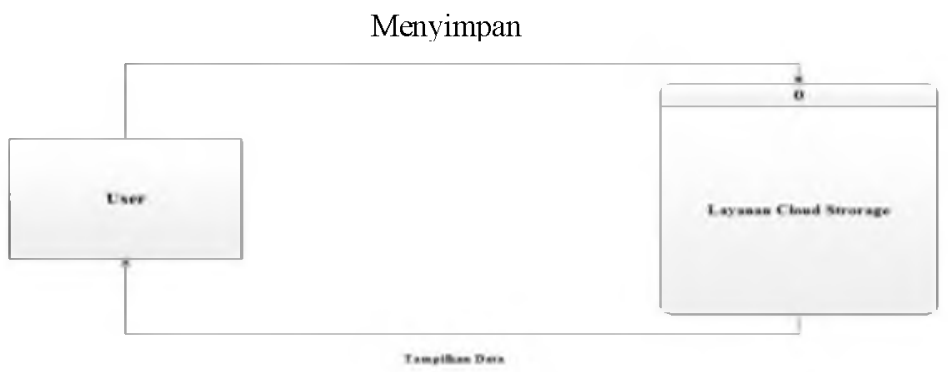

Gambar 2. Diagram Konteks

\subsubsection{DFD Level 0}

Data Flow Diagram yang digambarkan pada perancangan ini merupakan gambaran dari data yang mengalir pada sistem dan keseluruan proses mulai dari pengguna melakukan settingsampai dengan pengguna melakukan streaming pada sistem. DFD level 0 ini telah memenuhi keseluruhan gambaran proses hingga data data yang dikelola dan dirancang kedalam beberapa bagian proses yang nantinya disediakan oleh sistem dan alur data yang mengalir dapat dilihat pada gambar 2 . Berikut pada gambar 2, rancangan Data Flow Diagram dari sistem. 


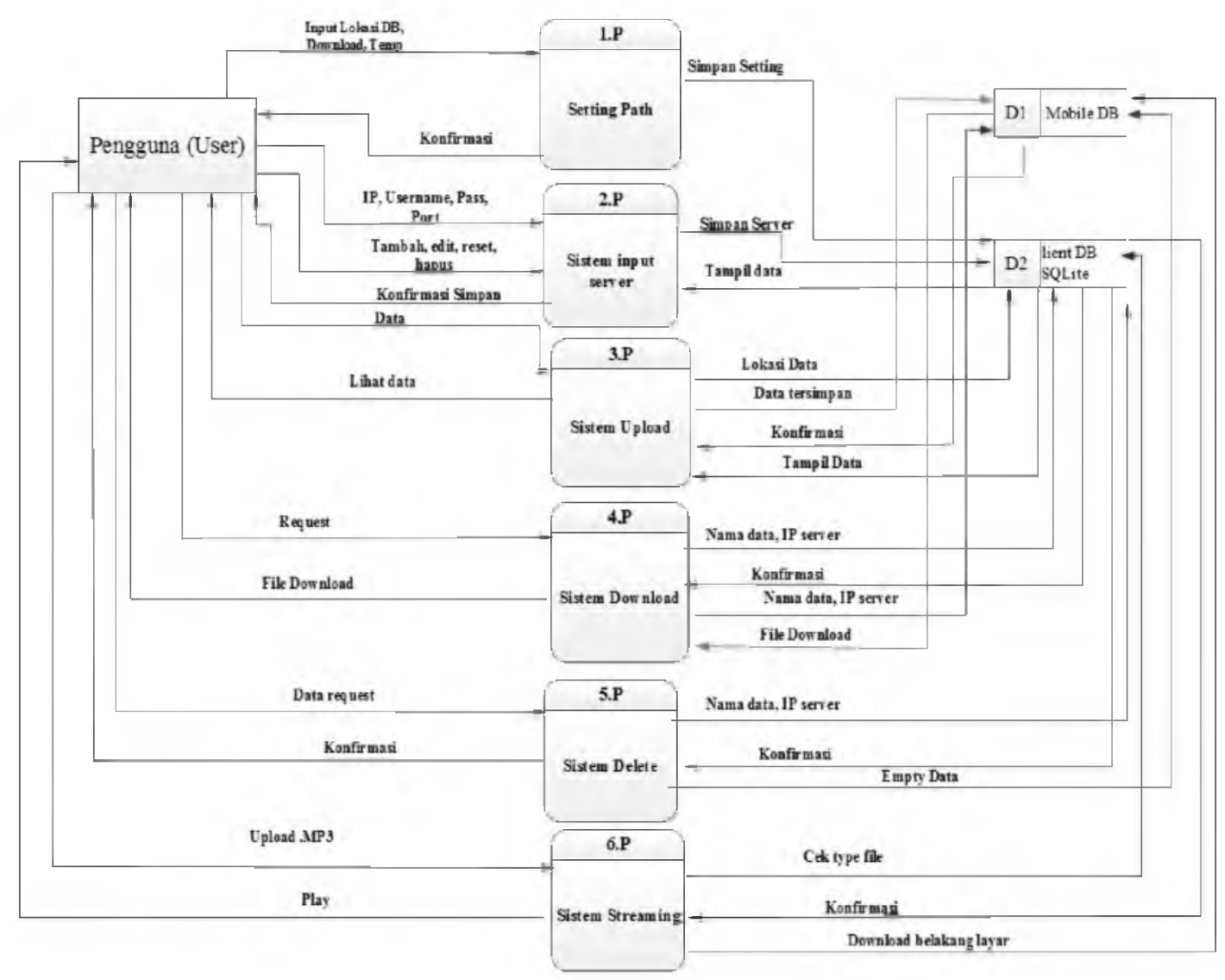

Gambar 3. DFD Level 0

\section{Hasil dan Pembahasan}

Berdasarkan analisis dari desain sistem yang telah dilakukan, maka telah diimplementasikan layanan cloud computing berbasisinfrastructure as a service menggunakan Android.Dalam aplikasi ini, menggunakan pemrograman java sebagai desain interface pada client , terdapat juga beberapa library yang digunakan pada sistem ini, seperti library commons-net-3.3.jar, j1.1.0.1.jar, JDK 1.7.

\subsection{Implementasi Halaman Setting}

Pada halaman setting ini, digunakan untuk melakukan setting path atau lokasi letak database maupun lokasi letak data yang di download dari smartphone berikut gambar implementasinya.

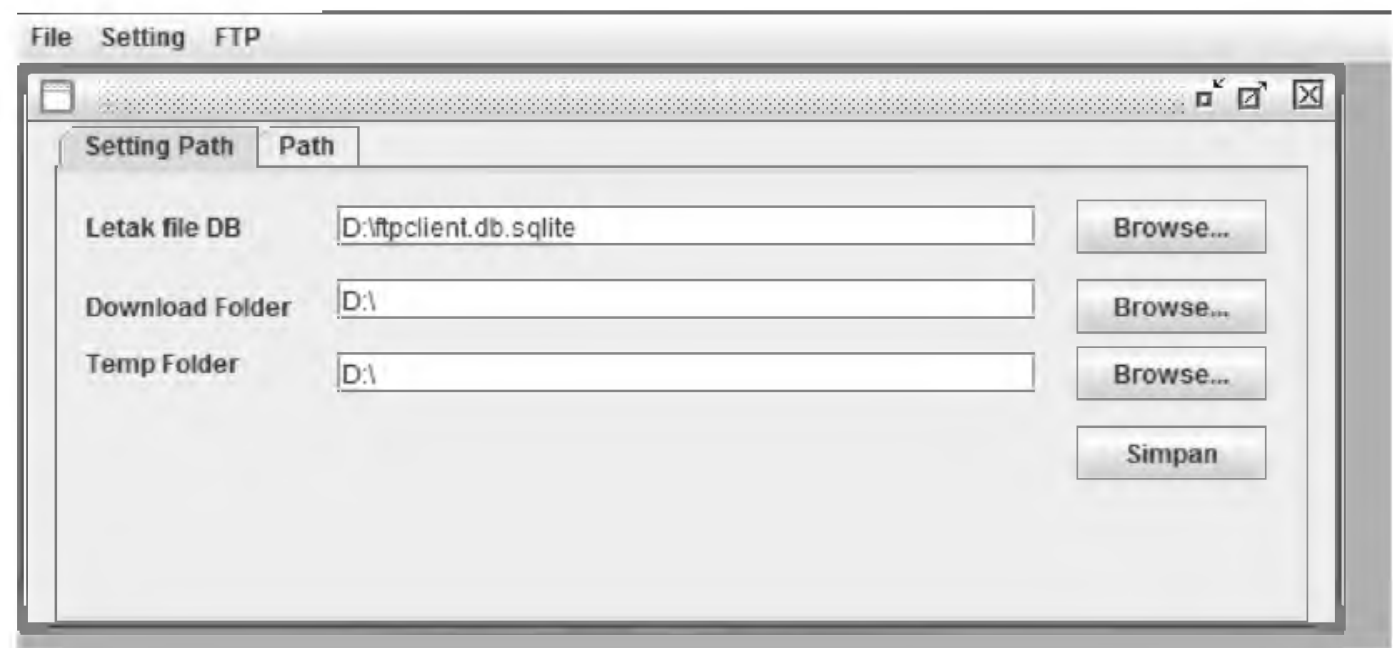

Gambar 4. Halaman Setting 


\subsection{Implementasi Halaman Server}

Gambar 4akan menampilkan halaman server, yang akan digunakan untuk melakukan koneksi ke smartphone, berikut gambar dari halaman server

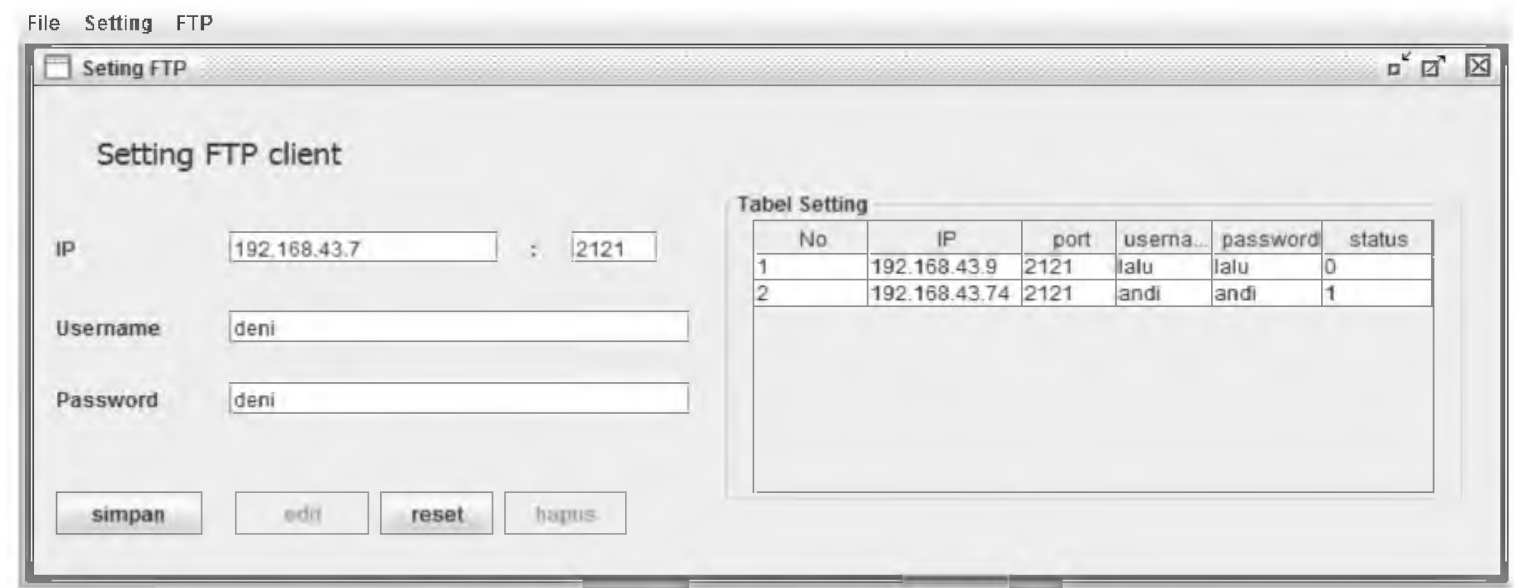

Gambar 5.Implementasi Halaman Server

\subsection{Implementasi Halaman Upload, Download, Delete dan Streaming}

Pada gambar 3 akan menampilkan implementasi halaman upload, Download, Delete dan Streaming yang akan ditemui pengguna ketika menggunakan layanan ini

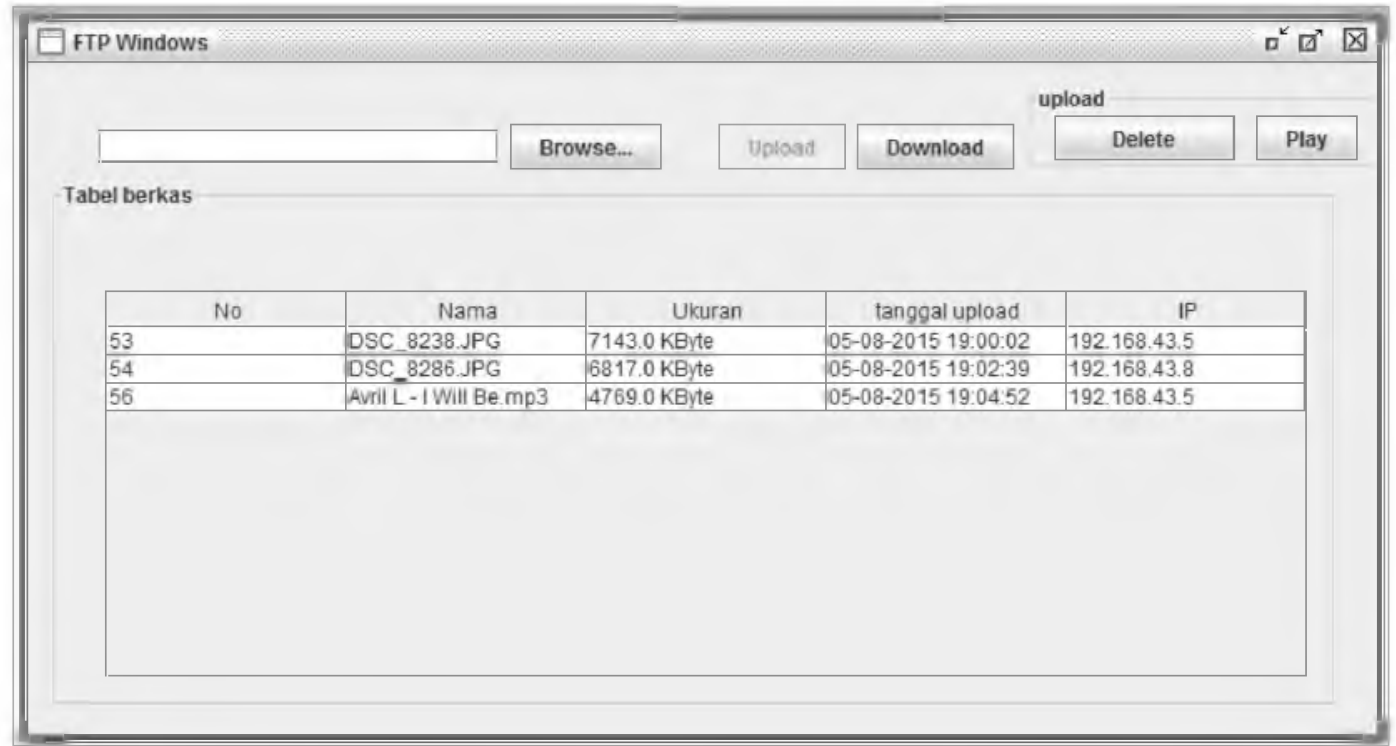

Gambar 6. Implementasi Halaman Upload, Download, Delete, Streaming

\subsection{Hasil Pengujian Sistem}

Pada tabel 1 dapat dilihat hasil pengujian sistem dengan menggunakan jaringan internet.Pada skema pengujian yang dilakukan yakni dengan menggunakan 3 smartphone dan 5 laptop yang bertugas sebagai client. Pengujian sistem ini dilakukan dengan 2 cara pengujian, yang pertama pengujian sistem, apakah sistem berjalan dengan baik menggunakan wirless local area network, dan yang kedua pengujian menggunakan kuisioner untuk mengetahui sistem berjalan baik atau tidak 


\subsubsection{Pengujian Menggunakan Wireless Local Area Network}

Pada pengujian yang dilaksanakan dilakukan satu kali akses uploadke server, oleh karena itu server yang bekerja pada tabel hanya server 1 . Namun, sistem sesungguhnya telah mendukung fungsi pergantian server secara sekuensial, yakni setelah server 1 melayani proses registrasi maka akan berganti pada server 2 untuk proses upload berikutnya dan berikutnya pada server 3 dan berulang sesuai dengan jumlah upload yang dilakukan. Hal ini menunjukkan sistem yang dibangun dapat berjalan dengan baik pada skema pengujian yang dilakukan.

Tabel 1. Hasil Pengujian Menggunakan WLAN

\begin{tabular}{|l|l|r|r|r|l|l|l|}
\hline No & Nama PC & HP1 & HP2 & HP3 & Ukuran file & Type file & Waktu \\
\hline 1 & PC1 & $\checkmark$ & & & $55.0 K B$ &. PNG & 2,2 detik \\
\hline 2 & PC2 & $\checkmark$ & $\checkmark$ & & $61.0 \mathrm{~KB}$ &. DOC & 2,4 detik \\
\hline 3 & PC3 & $\checkmark$ & $\checkmark$ & $\checkmark$ & $5621.0 \mathrm{~KB}$ &. PPT & 2,9 detik \\
\hline 4 & PC4 & $\checkmark$ & & & $665.0 \mathrm{~KB}$ &. PDF & 3,8 detik \\
\hline 5 & PC5 & $\checkmark$ & $\checkmark$ & & $4757.0 \mathrm{~KB}$ &. MP3 & 17 detik \\
\hline
\end{tabular}

\subsubsection{Pengujian Menggunakan Kuisioner}

Pada pengujian menggunakan kuisioner, bertujuan untuk mengetahui apakah sistem bekerja dengan baik atau tidak, dari 30 responden yang sudah mengisi kuisioner, sudah didapatkan hasil dari uji aplikasi menggunakan kuisioner ini, yang dihitung menggunakan metode likert. Berikut hasil dari pengujian tersebut.

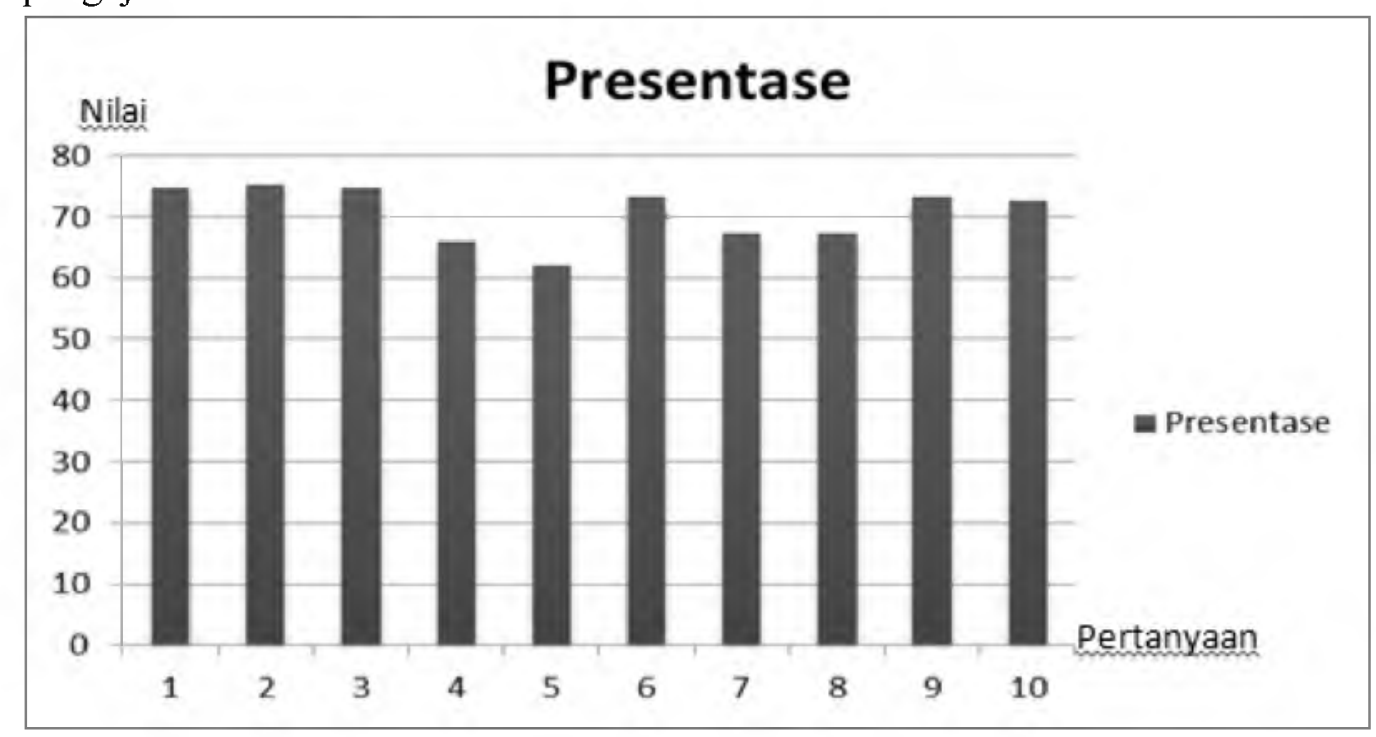

Gambar 7 Hasil Pengujian Menggunakan Kuisioner

Pada gambar 7 sudah didapat hasil dari pengujian kuisioner yang dibuat kedalam grafik sehingga mempermudah dalam membaca hasil pengujian sistem. Hasil yang sudah didapat dari pengujian menggunakan kuisioner dan dihitung dengan metode likert adalah 70,66\%, maka dapat disimpulkan bahwa pengujian menggunakan kuisioner termasuk dalam kriteria "Baik".

\section{Kesimpulan Dan Saran}

Kesimpulan yang diperoleh dari hasil analisa dan pengujian aplikasi cloud computingadalah sebagai berikut .

1. Pemanfaatan smartphone untuk membangun cloudcomputing dengan layanan share memori dapat digunakan untuk menyimpan dan melakukan pengolahan data pada sistem. 
2. Aplikasi untuk menerapkan cloudcomputing sudah berhasil rancang bangun dan diujikan pada jaringan komputer.

3. Berdasarkan hasil uji pengguna menggunakan metode likert menunjukkan bahwa sistem dapat berjalan dengan baik

Dalam aplikasi ini juga memiliki saran yang dapat digunakan sebagai pengembangan aplikasi selanjutnya, sebagai berikut.

1. Aplikasi dapat dikembangkan lagi dengan melakukan streaming bukan dalam format .mp3 saja, tapi dapat melakukan streaming dalam format AVI, MP4 (MPEG-4), 3GP, FLV, dan sebagainya.

2. Pada smartphone yang bertugas sebagi media penyimpanan, hanya menerapkan servercloud secara bergiliran, jadi untuk selanjutnya bisa dikembangkan sistem loadbalancing, sehingga jika terjadi kehabisan memori pada smartphone, bisa langsung di alihkan ke smartphone lainnya.

3. Aplikasi dapat dikembangkan dengan melakukan pencarian server yang aktif secara dinamis, pada aplikasi ini sendiri, server masih dilakukan secara statis.

\section{Daftar Pustaka}

Afdal.2013. Studi Perbandingan Layanan Cloud Computing. Aceh: Jurnal Rekayasa Elektronika vol.10.

Ashari, Ahmad., Setiawan,Herri.2011. Cloud Computing: Solusi ICT?. Palembang: Jurnal Sistem Informasi (JSI), Vol. 3, No. 2.

Budiyanto, Alex. 2012. Pengantar Cloud Computing. Yogyakarta: Komunitas Cloud Computing Indonesia.

Buyya,Rajkumar. Broberg, james. Goscinzki, Andrezj. 2012. Cloud Computing: Principles and Paradigms. New jersey:John Wiley \& Sons, Inc.

Falich, Joseph S., George, Joey F., Hoffer, Jeffery A.2004.Essential of System Analysis and Design Second edition. New Jersey: Pearcon Education, Inc.

Jatun,Martin Gilje., Gansen Zhao,Gansen., Vasilakos,Athanasios., Ahlmann Nyre, Asmund., Alapnes, Stian., Tang, Yong. 2012. The Design of A Redundant Array of Independent NetStorages for Improved Confidentiality in Cloud Computing. Jurnal Of cloud computing.

Moedjiono.2010.CLOUDCOMPUTING: Gelombang informatisasi Layanan Dunia Bisnis Masa Depan. Jurnal TELEMATIKA MKOM, Vol. 2 No.2.

Munteanu, Victor Ion., Sandru, Calin., Petcu,Dana. 2012. Multi-cloud Resource Management: Cloud Service Interfacing. Jurnal of Cloud computing.

Ramadhan, Zuhri. 2011.Aspek Keamanan pada Cloud Computing.Jurnal Ilmiah abdi ilmu, Vol.4 No. 2. ISSN: 1979-5408.

Sulistyowati, luchi., Sulistiyo, Wiwin. 2012. Implementasi Layanan Cloud Computing sebagai Infrastructure as A Service untuk Penyediaan Web server. Jurnal teknologi Informasi-Aiti.

Valacich,Josep s., George,Joey F., Hoffer,Jeffery A. 2012. Essentials of Systems Anlysisand Design. USA: Prentice Hall.

Wibisono Setyawan., Munawaroh Siti. 2012. Sistem Informasi Manajemen Puskesmas (Simpuskesmas) berbasis Cloud Computing. Jurnal Teknologi Informasi DINAMIK Volume 17, No. 2. 
Whitten, Jeffery L., Lonnie D. Bentley, Lonnie D., Dittman, Kevin C. 2004. Metode Systems Analysis and Design Methods. The Mcgraw Companies, Inc. 